\title{
The role of autonomic control in cardiovascular system:
}

summary of basic principles

\section{Uloga autonomne kontrole kardiovaskularnog sistema: osnovni principi}

Branislava Medić

Institut za farmakologiju, kliničku farmakologiju i toksikologiju, Medicinski fakultet Univerziteta u Beogradu

Kontakt: brankicamedic@gmail.com

Introduction

The autonomic nervous system (ANS) is predominantly an efferent system which transmits impulses from the central nervous system (CNS) to peripheral organs. Its effects include control of heart rate (HR) and force of heart contraction, constriction and dilatation of blood vessels, etc. Most of the fibers in autonomic system are efferent (exception are some afferent fibres that innervate the baroreceptors and chemoreceptors in the carotid sinus and aortic arch and have a role in control of HR, blood pressure etc.). The actions of autonomic nerves are mediated by the release of neurotransmitters that bind to specific cardiac receptors and vascular receptors (1).

The medulla is a major site in the brain for regulating outflow to the heart and blood vessels. It contains cell bodies for both sympathetic and parasympathetic sections. The nucleus tractus solitarius (NTS) of the medulla receives sensory input from different systemic and central receptors (e.g., baroreceptors and chemoreceptors). The hypothalamus and higher centers modify the activity of the medullary centers and are particularly important in stimulating cardiovascular responses to emotion and stress (e.g., exercise, thermal stress) (2).

Regarding anatomical and functional differences, the ANS is divided into two separate divisions - parasympathetic and sympathetic.

The parasympathetic system in human body origins from craniosacral division. Nervus vagus (or 10th cranial nerve) represents the cranial preganglionic outflow of the parasympathetic nervous system (PNS) and the spinal cord parts of S2-S4 sacral spinal nerves serve as sacral part. The short postganglionic neurons are located near effector organs (e.g.heart, trachea, lung, liver, exocrine glands, intestines, kidney, urinary bladder, etc. ).

The parasympathetic postganglionic fibers are cholinergic. Acetylcholine is the predominant neurotransmitter from the parasympathetic nervous system, in both the preganglionic and postganglionic neurons.
Acetylcholine can bind to two types of cholinergic receptors called nicotinic and muscarinic receptors. Muscarinic receptors are located in the membranes of effector cells at the end of postganglionic parasympathetic nerves and at the ends of cholinergic sympathetic fibers. Responses from these receptors are excitatory and relatively slow. The nicotinic receptors are located at synapses between pre- and post-ganglionic neurons of the sympathetic and parasympathetic pathways. Nicotinic receptors in contrast to muscarinic receptors produce rapid, excitatory responses.

It should be pointed out that is vagal tone declines with aging. It has been shown that only regular dynamic exercise is the stimulus to increase vagal tone (3).

In the sympathetic nervous system, on the other hand, preganglionic neurons originate from the thoracolumbar region of the spinal cord specifically at T2 to L1, and travel to a ganglion where synapse with a postganglionic neuron. From there, the long postganglionic neurons extend across most of the body (4).

While the preganglionic neurons of both the sympathetic and parasympathetic system secret acetylcholine (ACh) which is why they are referred to as cholinergic, the majority of the postganglionic sympathetic fibers released norepinephrine, which activates adrenergic receptors on the peripheral target tissues. The activation of target tissue receptors causes the effects associated with the sympathetic system (5).

\section{Parasympathetic and sympathetic receptors in cardiovascular system}

When we know the basics of anatomy of ANS, it is important to repeat the role of parasympathetic and sympathetic innervations regarding its role in cardiovascular system. The heart is innervated by vagal and sympathetic fibers. 


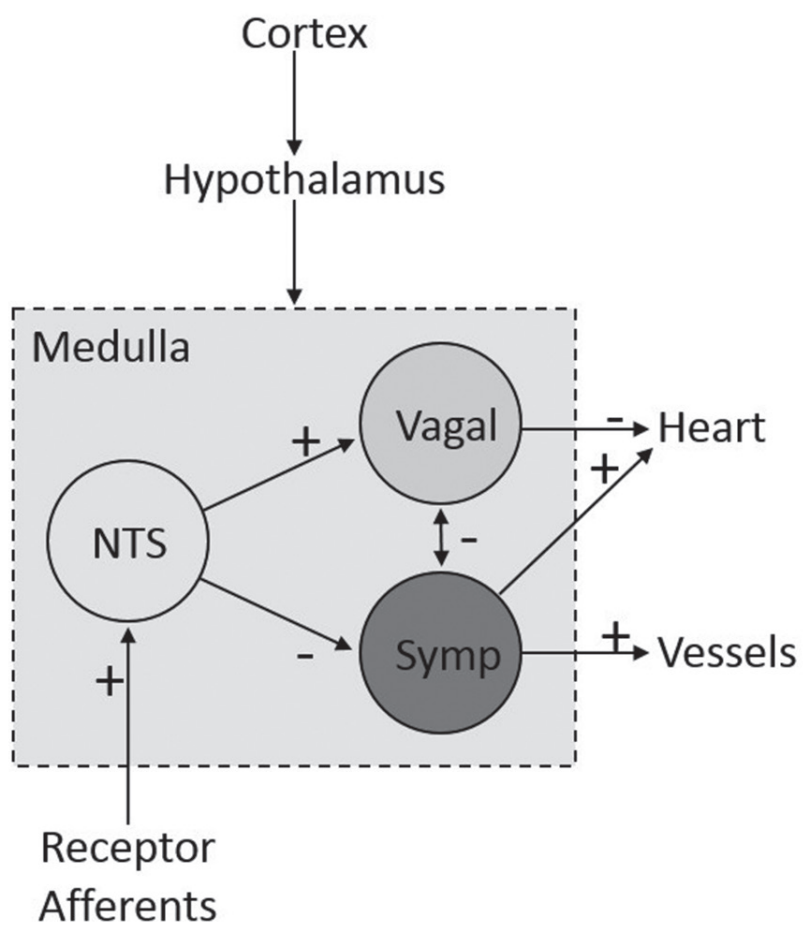

Graph 1. Schematic representation of connection between CNS, ANS and cardiovascular system (adapted from reference 2)

The right vagus nerve primarily innervates the SA node, while the left vagus innervates the AV node. Sympathetic efferent nerves are present throughout the atria (especially in the SA node) and ventricles, including the conduction system of the heart (2).

In relation to the cardiovascular system the parasympathetic nervous system has two different kinds of muscarinic receptors: the M2 and M3 receptors. The M2 receptors are expressed in the heart, especially in nodal and atrial tissue. The binding of acetylcholine to M2 receptors leads to decreasing in heart rate (negative chronotropic effect). This is achieved by slowing the rate of depolarization, as well as by reducing the conduction velocity through the atrioventricular node. Additionally, the activation of M2 receptors reduce the overall cardiac output and lead to decrease in force of myocardial contractility (negative inotropic effect). Beside that, stimulation of the parasympathetic system contrivutes to inhibition of AV node conduction velocity (negative dromotropic effect) and decrease in excitability of heart (negative bathmotropic effect).

It is important to notice that most blood vessels in body do not have parasympathetic innervation, but the M3 receptors are mainly expressed in vascular endothelium. The predominate effect of M3 receptor activation is dilatation of the vessels, by stimulating nitric oxide production by vascular endothelial cells. M3 receptors impact afterload and vascular resistance which can again alter cardiac output and blood pressure.
Currently, it is a matter of debate whether parasympathetic stimulation can exhibit negative inotropic effects, as the vagus nerve does not directly innervate cardiomyocytes other than that of the sinoatrial and atrioventricular nodes, however, recent in vivo studies may suggest otherwise, at least in the atrium $(1,6)$.

In contrast to the heart, most vessels (arteries and veins) only receive sympathetic innervation, while capillaries receive no innervation. The actions of catecholamines are mediated by $\alpha$ and $\beta$ receptors. In the cardiovascular system there are $\beta 1, \beta 2, \alpha 1$, and $\alpha 2$ adrenergic receptors. Enhanced sympathetic activity is particularly important during exercise, emotional stress, and during hemorrhagic shock.

$\beta 1$ adrenergic receptors are expressed in the heart (in the SA node, AV node, and on atrial and ventricular coronary circulation). Stimulation by the sympathetic nervous system results in the following effects on the heart: positive chronotropic effect (increase in heart rate), positive inotropic effect (increase of contractility), positive dromotropic effect (enhancement of conduction) and positive bathmotropic effect (increase in excitability of heart). There are also some low expressions of $\beta 2$ and $\alpha 1$ receptors in cardiomyocytes, but their role is not yet fully clarified (7).

al adrenergic receptors are expressed in vascular smooth muscle proximal and stimulate vasoconstriction. Sympathetic nerve fibers tonically release norepinephrine, which activates $\alpha 1$-adrenergic and $\beta 2$-adrenergic receptors on blood vessels thereby providing basal vascular tone. Since there is greater $\alpha 1$-adrenergic than $\beta 2$-adrenergic receptor distribution in the arteries, activation of sympathetic nerves causes vasoconstriction and increases the systemic vascular resistance primarily via al receptor activation.

However, $\beta$-adrenergic receptors show greater affinity for epinephrine than for norepinephrine. Therefore, circulating epinephrine at low concentrations activates only $\beta 1$-adrenergic (mainly in the heart) and $\beta 2$-adrenergic (mainly in vessels) receptors, which increase cardiac output and cause vasodilation, respectively.

a2 adrenergic receptors are expressed in vascular smooth muscle distal from sympathetic nerve terminals. Their activation also elicits vasoconstriction.

In addition to the ANS, cardiovascular function is also influenced by numerous endocrine hormones. Released from the adrenal gland, epinephrine and dopamine (and ultimately, norepinephrine) are all involved in the initiation of the "fight-or-flight" response, while vasopressin, renin, angiotensin, aldosterone, and atrial natriuretic peptide are all involved in water reabsorption for the purpose of blood pressure regulation $(3,8)$. 
Table 1. The effects of sympathetic and parasympathetic system on heart and blood vessels (adapted from reference 2)

\begin{tabular}{|c|c|c|}
\hline & Sympathetic system & Parasympathetic system \\
\hline \multicolumn{3}{|l|}{ Heart } \\
\hline Chronotropy (rate) & Increased heart rate $(\mathrm{HR}): ß 1$ (and $ß 2)+++$ & Decreased heart rate (HR) - - - \\
\hline Inotropy (contractility) & $\begin{array}{l}\text { Increased force of contraction: } ß 1 \text { (and } ß 2 \text { ) } \\
+++\end{array}$ & Decreased force of contraction - \\
\hline $\begin{array}{l}\text { Dromotropy (conduction } \\
\text { velocity) }\end{array}$ & Increased conduction velocity ++ & Decreased conduction velocity - - - \\
\hline Bathmotropy (excitability) & Increased excitability ++ & Decreased excitability - - \\
\hline \multicolumn{3}{|l|}{ Blood Vessels } \\
\hline Arterial constriction & Constriction $(\alpha 1)$, dilatation $(ß 2)+++$ & 0 \\
\hline Venous constriction & Constriction $(\alpha 1)$, dilatation $(B 2)+++$ & 0 \\
\hline
\end{tabular}

\section{The Effects of ANS on Vascular Function}

Several reports have demonstrated an effect originating from the ANS on vascular function. Hijmering et al. demonstrated that sympathetic stimulation signifycantly impairs the flow-mediated dilation response via an alpha-adrenergic mechanism (9). The inhibitory effect of sympathetic activation is limited to shear mediated NO release; however, the precise mechanism has not been revealed. A similar finding was reported by Lemitsu, who demonstrated an inhibitory effect of exercise-induced sympathetic stimulation on NO metabolites in rat heart tissue (10).

In contrast, in young healthy volunteers, flow-mediated dilation in the femoral artery was not modified by sympathetic activation induced by the cold pressor test, a potent nonbaroreflex sympathoexcitatory stimulus whereas modification did occur in older healthy subjects $(11,12)$. Conversely, it has been demonstrated that ANS denervation alters endothelial function in animal studies (13).

In humans, ANS modulation by a 2 -adrenoreceptor agonists has also been shown to improve endothelial dysfunction in patients with hypertension (14). These findings suggest a contribution of sympathetic nervous tone on the baseline condition of vascular function.

In addition, experimental data suggest that exaggerated sympathetic nervous activity modifies other aspects of endothelial function $(15,16)$.

\section{Effect of Vascular Function on the ANS}

Although the ANS may impact on vascular function, the reverse may also be true. However, reports demonstrating a vascular contribution to regulation of the ANS are relatively limited compared with the evidence for an effect of the ANS on vascular function. Animal experiments showed that removal of the endothelium increased the release of norepinephrine from sympathetic nerve terminals in rabbit carotid artery (17).

NO is one important agent that appears to modulate sympathetic nervous system activity during blood pressure control. Although the mechanisms by which NO modulates neuronal activity are unclear, research suggests that $\mathrm{NO}$ alters neuronal responses to excitatory amino acids (18). Experiments in animal models, particularly the streptozotocin-induced diabetic rat, have shown that reduced nerve blood flow occurs very early after diabetic induction (19). The perfusion deficit is sufficient to cause endoneurial hypoxia, suggesting that endoneurial hypoxia may produce many of the observed morphological and biochemical changes in experimental diabetic neuropathy (20). Another report showed that NO acts as a sympatho-inhibitory substance within the central nervous system. Plater et al. demonstrated that endothelial dysfunction may predispose patients with diabetes to impairments in peripheral neural conduction (21). 
In recently diagnosed patients with diabetes followed for 3 years, higher von Willebrand factor levels predicted a subgroup of patients with diabetes who subsequently developed deficits in lower limb nerve conduction velocity. However, the direct effect of the endothelium on alterations in neurotransmitter release, reuptake, or receptor sensitivity requires further investigation (22).

\section{Pharmacological or Therapeutic Interventions to Modify ANS Pathways: Beta-blocking agents}

The most popular pharmacological agents used to modify the activity of the ANS are beta-adrenergic receptor blockade agents. However, the effect of these agents on vascular function has not been fully clarifyed. In animal experiments, beta-adrenergic receptor blockade may protect endothelial cells from the negative effect of heightened sympathetic nerve activity (23). In contrast, there are contradictory reports for beta-blocking agent administration in humans. For instance, in subjects with type 2 diabetes and hypertension, atenolol did not improve endothelial function, whereas losartan improved endothelial function and decreased oxidative stress (24). Other studies generally failed to show a beneficial effect of beta-adrenergic receptor blockade $(25,26)$.

In contrast, men treated with atenolol demonstrated a decline in circulating endothelin, suggesting a gender-specific beneficial effect of beta-blocking agents on vascular function (27). Matsuda et al. also demonstrated that treatment with carvedilol for 4 months improved brachial flow-mediated dilation among patients with ischemic heart disease (28).

Thus, the effect of beta-blocking agents on vascular function remains controversial and requires further investigation. In addition, little has been reported about the effect of $\alpha$-adrenergic blocking agents on vascular function.

\section{Conclusion}

In conclusion, this paper is an attempt to gather in one place just basic principles regarding primarily connection between ANS and cardiovascular function.

It should be pointed out that cardiovascular system is controlled and influenced by not only a unique intrinsic conduction system, but is also heavily determined by the autonomic nervous system as well as the endocrine system. The cardiovascular system responds to not only acute but also chronic changes in blood pressure and homeostasis.
The role of autonomic nervous system on cardiovascular function is significant and undeniable and understanding of these principles represents the basis for further learning and research, not only in the physiological and pathophysiological, but also in the pharmacological and clinical sense.

\section{References:}

1. Vaseghi M, Shivkumar K. The role of the autonomic nervous system in sudden cardiac death. Prog Cardiovasc Dis; 50(6): 404-19.

2. Klabunde RE. Cardiovascular Physiology Concepts 2nd ed. Philadelphia: Lippincott Williams\&Wilkinns; 2012.

3. Gordan R, Gwathmey JK, Xie LH. Autonomic and endocrine control of cardiovascular function. World J Cardiol; 7(4): 204-14.

4. Lüscher TF, Yang Z, Tschudi M. Interaction between endothelin-1 and endothelium-derived relaxing factor in human arteries and veins. Circ Res 1990; 66: 1088-94.

5. Böhm F, Pernow J. The importance of endothelin-1 for vascular dysfunction in cardiovascular disease. Cardiovasc Res 2007; 76: 8-18.

6. Freeman JV, Dewey FE, Hadley DM, Myers J, Froelicher VF. Autonomic nervous system interaction with the cardiovascular system during exercise. Prog Cardiovasc Dis. 2006; 48(5): 342-62.

7. Grassi G. Assessment of sympathetic cardiovascular drive in human hypertension: achievements and perspectives. Hypertension 2009; 54: 690-7.

8. Mann DL, Zipes DP, Libby P, Bonow RO. Braunwald's Heart Disease: Textbook of Cardiovascular Medicine. 10th ed. Philadelphia, Pennsylvania: Elsevier - Health Sciences Division; 2014.

9. Hijmering ML, Stroes ES, Olijhoek J, et al. Sympathetic activation markedly reduces endothelium-dependent, flow-mediated vasodilation. J Am Coll Cardiol 2002; 39: 683-8.

10. Iemitsu $M$, Miyauchi $T$, Maeda $S$, et al. Intense exercise causes decrease in expression of both endothelial NO synthase and tissue NOx level in hearts. Am J Physiol Regul Integr Comp Physiol 2000; 279: R951-9.

11. Victor RG, Leimbach WN, Seals DR, et al. Effects of the cold pressor test on muscle sympathetic nerve activity in humans. Hypertension 1987; 9: 429-36.

12. Thijssen DH, de Groot P, Kooijman M, et al. Sympathetic nervous system contributes to the age-related impairment of flow-mediated dilation of the superficial femoral artery. Am J Physiol Heart Circ Physiol 2006; 291: H3122-9.

13. Burnstock G. Local mechanisms of blood flow control by perivascular nerves and endothelium. J Hypertens Suppl 1990; 8: S95-106.

14. Topal E, Cikim AS, Cikim K, et al. The effect of moxonidine on endothelial dysfunction in metabolic syndrome. Am J Cardiovasc Drugs 2006; 6: 343-8.

15. Coutinho GC, Durieu-Trautmann O, Strosberg AD, et al. Catecholamines stimulate the IFN-gamma-induced class II MHC expression on bovine brain capillary endothelial cells. J Immunol 1991; 147: 2525-9. 
16. Born GV. Recent evidence for the involvement of catecholamines and of macrophages in atherosclerotic processes. Ann Med 1991; 23: 569-72

17. Tesfamariam B, Weisbrod RM, Cohen RA. Cyclic GMP modulators on vascular adrenergic neurotransmission. J Vasc Res 1992; 29: 396-404.

18. Dias AC, Colombari E, Mifflin SW. Effect of nitric oxide on excitatory amino acid-evoked discharge of neurons in NTS. Am J Physiol Heart Circ Physiol 2003; 284: H234-40.

19. Tuck RR, Schmelzer JD, Low PA. Endoneurial blood flow and oxygen tension in the sciatic nerves of rats with experimental diabetic neuropathy. Brain 1984; 107 (Pt 3): 935-50.

20. Patel KP, Li YF, Hirooka Y. Role of nitric oxide in central sympathetic outflow. Exp Biol Med (Maywood) 2001; 226: 814-24.

21. Plater ME, Ford I, Dent MT, et al. Elevated von Willebrand factor antigen predicts deterioration in diabetic peripheral nerve function. Diabetologia 1996; 39: 336-43.

22. Harris KF, Matthews KA. Interactions between autonomic nervous system activity and endothelial function: a model for the development of cardiovascular disease. Psychosom Med 2004; 66: 153-64.
23. Skantze HB, Kaplan J, Pettersson K, et al. Psychosocial stress causes endothelial injury in cynomolgus monkeys via beta1-adrenoceptor activation. Atherosclerosis 1998; 136: 153-61.

24. Flammer AJ, Hermann F, Wiesli P, et al. Effect of losartan, compared with atenolol, on endothelial function and oxidative stress in patients with type 2 diabetes and hypertension. J Hypertens 2007; 25: 785-91.

25. Higashi Y, Sasaki S, Nakagawa K, et al. A comparison of angiotensin-converting enzyme inhibitors, calcium antagonists, beta-blockers and diuretic agents on reactive hyperemia in patients with essential hypertension: a multicenter study. J Am Coll Cardiol 2000; 35: 284-91.

26. Schiffrin EL, Deng LY. Comparison of effects of angiotensin I-converting enzyme inhibition and beta-blockade for 2 years on function of small arteries from hypertensive patients. Hypertension 1995; 25: 699-703.

27. Seljeflot I, Arnesen H, Andersen P, et al. Effects of doxazosin and atenolol on circulating endothelin-1 and von Willebrand factor in hypertensive middle-aged men. J Cardiovasc Pharmacol 1999; 34: 584-8.

28. Matsuda Y, Akita H, Terashima M, et al. Carvedilol improves endothelium-dependent dilatation in patients with coronary artery disease. Am Heart J 2000; 140: 753-9. 